\title{
GLUCOSE VARIATIONS AND THEIR IMPACT ON THE TREATMENT RESPONSE IN ADVANCED COLORECTAL CANCER
}

\author{
Jonathan Souza Sarraf ${ }^{1}$, Taynah Cascaes Puty ${ }^{1}$, Gabriel Seabra Aguiar de Brito, \\ Rebeca da Paixão Cleophas Cunha ${ }^{1}$, Gércia Samilles Almeida Lira', \\ Luis Eduardo Werneck de Carvalho ${ }^{1}$, Luiz Fernando Affonso Fonseca ${ }^{2}$, Fernando Adami ${ }^{3}$ \\ ${ }^{1}$ Oncologica Brasil - Education and Research, Brazil \\ ${ }^{2}$ Faculty of Medicine of $A B C$, Brazil \\ ${ }^{3}$ Epidemiologic Laboratory and Data Analysis, Faculty of Medicine of ABC, Brazil
}

\begin{abstract}
INTRODUCTION: Serum glucose is commonly associated with a bad clinical prognosis in many diseases, including colorectal cancer (CRC). However, the real impact of glucose variation (GV) on the treatment and prognosis of CRC patients is unknown. Due to the absence of information, this study aimed to correlate GV and treatment response in advanced CRC.
\end{abstract}

MATERIALS AND METHODS: Thirty-eight CRC patients with stage III and IV disease were studied. The selected ones were those who have had two consecutive computed-tomography scans and more than one serum glucose (SG) test between the CT scans, which left 19 people of the original group.

RESULTS: The mean age of the 19 analyzed subjects was 58.6 years $\mathrm{SD}=18.26$; CI 95\% $50.9-71.0$. Most of the patients were men (59\%), with Wilt-Type KRAS mutation (63.2\%), without metastasis (71\%) and at a clinical stage III (73.3\%). No statistically significant value was found $(\mathrm{p}=0.126)$ between $\mathrm{GV}$ and treatment response in advanced CRC patients.

CONCLUSION: These findings cannot indicate a direct association between GV and treatment response in advanced CRC patient, but open space for evaluation of new methods of handling glucose variations in attempt to get a better understanding about how glucose may influence the CRC prognosis.

Keywords: colorectal cancer, glucose variation, treatment response

Address for correspondence:

Jonathan Souza Sarraf

570 Visconde de Souza Franco Av

660053-00 Belém, PA

Brazil

e-mail: jonathan.sarraf@oncologica.com.br

Received: October 24, 2017

Accepted: November 8, 2017

\section{INTRODUCTION}

Colorectal cancer (CRC) is linked to high morbidity and mortality, mainly in the advanced stages (1). In Brazil, 2016, it is estimated that there were 16 600 new cases for men and 17620 for women (2).

It is important to understand the influence of serum glucose (SG) in CRC tumorigenesis and its role in tumor cell behavior, cancer microenvironment. It may be important for monitoring CRC pa- 
tients. When there are high levels of SG and prolonged use of insulin, the risk of developing CRC is increased (3-6). The intracellular glucose metabolism has an important role in cellular proliferation and the increase of tumor size in CCR $(7,8)$.

The glucose variation (GV) as a relevant prognosis factor in CRC patients is still little researched. However, SG is considered a risk predictor for biological outcomes in patients in intensive care unit (ICU) $(9,10)$ and in diabetes mellitus patients $(11,12)$.

Therefore, this study aims to initiate a discussion about the relation between SG variation and treatment response, as well as the methods to handle the analysis of this variation in patients with advanced CRC.

\section{MATERIALS AND METHODS}

Retrospective cohort study, in the period from January 2012 to July 2015 in the Oncológica do Brasil Hospital, in Belém, Pará. Clinical records of thirtyeight individuals with colorectal cancer were studied. Out of them were excluded those who did not have: i) fasting SG test during the first CT scan examination; ii) at least two fasting SG tests between the first image examination and the subsequent one; iii) computed tomography scan (CT scan) after the diagnosis and subsequent CT scan. A total of 19 fit subjects remained in the study.

The glucose test was conducted in patients fasting for at least 8 hours prior to the test. The results of the CT scan were obtained through an evaluation by a radiologist. The variation of the SG level was defined as all SG standard deviations (SD) for each patient.

The treatment response (yes or no) was classified by radiological response (RECIST). Treatment response (yes) was defined as tumor size decrease or disease stabilization. Treatment response (no) was defined as increased tumor growth (increase $>10 \%$ in tumor volume) and/or metastases.

Data were extracted in duplicate, and then an assessment of the data consistency was performed. The diagnosis of CRC was defined as the start of the study follow-up ( $\mathrm{t} 0$ ) and the second image diagnostics was at the end of study follow-up (t1) (Fig. 1).

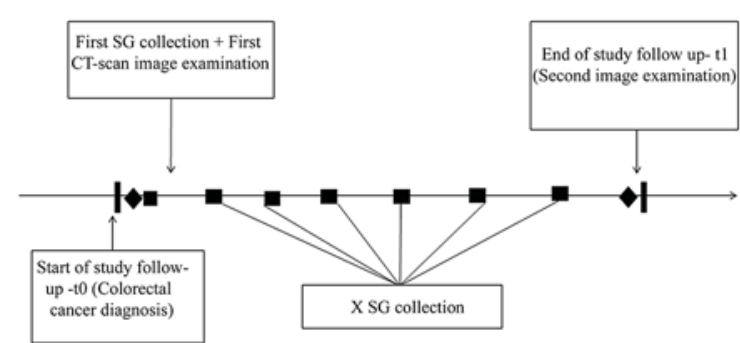

Fig. 1. A patient's follow-up diagram. SG= serum glucose; CT-Scan: computed tomography scan

The study was approved by the Ethics Committee of the Faculty of Medicine of $A B C$, number 1.173.508.

\section{RESULTS}

The mean age of the 19 analyzed subjects was 58.6 years $(\mathrm{SD}=18.26$; CI 95\% 50.9 - 71.0). Table 1 shows the epidemiological and clinical characteristics of the individuals. The test's power, calculated afterwards, was $50 \%$. In addition to the sample, we used for this count the following parameters: mean of serum glucose levels and SD of serum glucose levels as treatment response, using $5 \%$ alpha.

The median follow-up time of subjects and time between the first and the second image diagnostics was 7.8 months (p25\%-75\%= $5.5 ; 18.7$ ) and 5 months

Table 1. Epidemiological and clinical characteristics of subjects with colorectal cancer (Belém, 2015)

\begin{tabular}{llll} 
Characteristics & N & \multicolumn{1}{l}{ CI-95\% } \\
Sex & & & \\
$\quad$ Male & 13 & 59.10 & $0.39 ; 0.87$ \\
$\quad$ Female & 9 & 40.90 & $0.12 ; 0.60$ \\
KRAS Mutation & & & \\
$\quad$ Wilt-Type KRAS & 12 & 63.20 & $0.39 ; 0.87$ \\
$\quad$ KRAS Mutation & 7 & 36.80 & $0.12 ; 0.60$ \\
Metastasis & & & \\
$\quad$ Peritoneal carcinomatosis & 1 & 5.26 & $-0.05 ; 0.16$ \\
Liver & 2 & 10.52 & $-0.04 ; 0.25$ \\
Bone & 1 & 5.26 & $-0.57 ; 0.16$ \\
Retroperitoneal & 1 & 5.26 & $-0.57 ; 0.16$ \\
$\quad$ Without metastasis & 14 & 73.70 & $0.51 ; 0.95$ \\
Clinical staging & & & \\
III & 14 & 73.70 & $0.51 ; 0.94$ \\
IV & 5 & 26.30 & $0.04 ; 0.48$ \\
\hline
\end{tabular}

Scripta Scientifica Vox Studentium, 2017;1(1):23-27 Medical University of Varna 


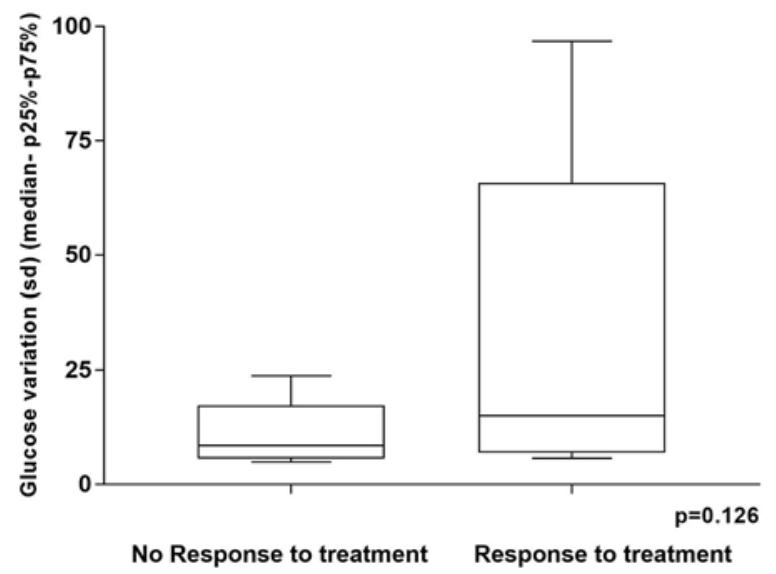

Fig. 2. Association between glucose variation (GV) and treatment response

$(\mathrm{p} 25 \%-75 \%=3.6 ; 8.0)$, respectively. The mean of number of glucose tests during the follow-up was 5.7 $(\mathrm{SD}=2.2)$.

On analyzing the association between $\mathrm{GV}$ and treatment response (Fig. 2) no statistically significant value was found $(\mathrm{p}=0.126)$.

\section{DISCUSSION}

No studies were found on the relation between the $\mathrm{GV}$ and response to treatment in individuals with cancer. Despite that, the influence of glucose levels $(13,14)$, insulin levels $(6,13,15)$, presence of diabetes mellitus (16) and metabolic syndrome presence $(5,17)$ are already related to the increased risk of CRC development $(6,13,16)$ and impact the prognosis of those patients $(5,14,16,17)$.

The mean age of the subjects analyzed (58.6 years) was similar to what other authors have reported (52.1 to 68 yeas) $(6,18-20)$. Moreover, the proportion of individuals identified with KRAS gene mutation $(36.8 \%)$ was also similar to the literature findings (27\% to $47 \%)(18-25)$, showing consistency with the results of previous studies.

$\mathrm{GV}$ is cited in studies as a risk factor for biological outcomes $(11,12,26)$. ICU data showed a large variation of glucose $(9,10)$ and blood pressure $(27)$, which may have a negative impact on the patients' prognosis. This raises a discussion about the variation, not in only glucose levels, interfering with biological outcomes. Thus, we began to think about the impact of methods of glucose measurement and how the follow-up fluctuations may be important for the CRC patients.

It is important to point out the great difficulty in establishing a consensus on the handling of glucose variation. Several studies report the use of standard deviation as a main measure $(9-11,28)$, but the coefficient of variation may also be used to measure it (9). The studies of heart rate variability are an example of the diverse methods for evaluating a given biological factor (29). Thus, the establishment of a method of measurement with the corresponding patterns could be relevant in understanding the glucose variations as a prognosis marker.

Sample size, the lack of a set time to follow up the individuals and the number of glucose tests may be highlighted as limiting factors of this research. However, the entry of new patients should increase the test's power to confirm or refute the indicated results of this study. In addition, these points could be corrected as an effort to perform more sensible analyses to assess the influence of follow-up time and the number of SG measurements in the proposed outcomes.

\section{CONCLUSION}

The reflection on new methods to assess the impact of metabolic factors is important for the understanding of the diverse influences of endogenous factors on the pathology prognosis. This study opens space for new debates that can encompass larger samples, control of other associated factors and evaluate new methods of handling glucose variations in attempt to achieve a better understanding about how glucose may influence the CRC prognosis.

\section{Acknowledgements}

We are grateful for all reviews by Thiago Hérick de Sá, PhD from Public Health Nutrition - University of São Paulo (USP) at the beginning of this study. His contributions were so important for the improvement of the methods and the quality of this article.

\section{Conflict of Interest}

The authors declare no conflict of interest 


\section{REFERENCES}

1. Lin JH, Zhang SM, Rexrode KM, Manson JE, Chan $\mathrm{AT}, \mathrm{Wu} \mathrm{K}$, et al. Association between sex hormones and colorectal cancer risk in men and women. Clin Gastroenterol Hepatol. 2013;11(4):419-424.e1. doi: 10.1016/j.cgh.2012.11.012

2. Instituto Nacional do câncer José de Alencar (INCA), Estimativa 2016/2017, 2016. http://www. inca.gov.br/wcm/dncc/2015/por-tipos.asp. (Accessed 23 de Janeiro 2016).

3. Limburg PJ, Stolzenberg-Solomon RZ, Vierkant RA, Roberts K, Sellers TA, Taylor PR, et al. Insulin, glucose, insulin resistance, and incident colorectal cancer in male smokers. Clin Gastroenterol Hepatol. 2006;4(12):1514-21.

4. Sharma A, Ng H, Kumar A, Teli K, Randhawa J, Record J, et al. Colorectal cancer: Histopathologic differences in tumor characteristics between patients with and without diabetes. Clin Colorectal Cancer. 2014;13(1):54-61. doi: 10.1016/j. clcc.2013.10.002

5. Shen Z, Ye Y, Bin L, Yin M, Yang X, Jiang K, et al. Metabolic syndrome is an important factor for the evolution of prognosis of colorectal cancer: survival, recurrence, and liver metastasis. Am J Surg. 2010 Jul;200(1):59-63. doi: 10.1016/j.amjsurg.2009.05.005

6. Shin HY, Jung KJ, Linton JA, Jee SH. Association between fasting serum glucose levels and incidence of colorectal cancer in Korean men: the Korean Cancer Prevention Study-II. Metabolism. 2014 Oct;63(10):1250-6. doi: 10.1016/j. metabol.2014.07.006

7. Martinez-Outschoorn U, Sotgia F, Lisanti MP. Tumor microenvironment and metabolic synergy in breast cancers: critical importance of mitochondrial fuels and function. Semin Oncol. 2014;41(2):195216. doi: 10.1053/j.seminoncol.2014.03.002

8. Estevez-Garcia P, Rivera F, Molina-Pinelo S, Benavent M, Gómez J, Limón ML, et al. Gene expression profile predictive of response to chemotherapy in metastatic colorectal cancer. Oncotarget. 2015;6(8):6151-9.

9. Egi M, Bellomo R, Stachowski E, French CJ, Hart G. Variability of blood glucose concentration and short-term mortality in critically ill patients. Anesthesiology. 2006;105(2):244-52.

10. Lazzeri C, Valente S, Chiostri M, D’Alfonso MG, Gensini GF. Prognostic impact of early glucose variability in acute heart failure patients.
Int J Cardiol. 2014;177(2):693-5. doi: 10.1016/j. ijcard.2014.09.150

11. Zhang XL, Lu JM, Shan GL, Yang ZJ, Yang WY. Association between glucose variability and adverse in-hospital outcomes for Chinese patients with acute coronary syndrome. Saudi Med J. 2010;31(10):1146-51.

12. Bragd J, Adamson U, Bäcklund LB, Lins PE, Moberg E, Oskarsson P. Can glycaemic variability, as calculated from blood glucose self-monitoring, predict the development of complications in type $1 \mathrm{di}$ abetes over a decade? Diabetes Metab. 2008;34(6 Pt 1):612-6. doi: 10.1016/j.diabet.2008.04.005

13. Colangelo LA, Gapstur SM, Gann PH, Dyer AR, Liu K. Colorectal cancer mortality and factors related to the insulin resistance syndrome. Cancer Epidemiol Biomarkers Prev. 2002;11(4):385-91.

14. Taniguchi L, Higurashi T, Uchiyama T, Kondo Y, Uchida E, Uchiyama S, et al. Metabolic factors accelerate colorectal adenoma recurrence. BMC Gastroenterol. 2014;14:187. doi: 10.1186/1471-230X-14-187

15. Yang YX, Hennessy S, Lewis JD. Insulin therapy and colorectal cancer risk among type 2 diabetes mellitus patients. Gastroenterology. 2004;127(4):1044-50.

16. Dehal AN1, Newton CC, Jacobs EJ, Patel AV, Gapstur SM, Campbell PT. Impact of diabetes mellitus and insulin use on survival after colorectal cancer diagnosis: the Cancer Prevention Study-II Nutrition Cohort. J Clin Oncol. 2012;30(1):53-9. doi: 10.1200/JCO.2011.38.0303

17. You J, Liu WY, Zhu GQ, Wang OC, Ma RM, Huang GQ, et al. Metabolic syndrome contributes to an increased recurrence risk of non-metastatic colorectal cancer. Oncotarget. 2015;6(23):19880-90.

18. Andreyev HJ, Norman AR, Cunningham D, Oates J, Dix BR, Iacopetta BJ, et al. Kirsten ras mutations in patients with colorectal cancer: the 'RASCAL II'study. Br J Cancer. 2001;85(5):692-6.

19. Andreyev HJ1, Norman AR, Cunningham D, Oates JR, Clarke PA. Kirsten ras mutations in patients with colorectal cancer: the multicenter "RASCAL" study. J Natl Cancer Inst. 1998 May 6;90(9):675-84.

20. Bader T, Ismail A. Higher prevalence of KRAS mutations in colorectal cancer in Saudi Arabia: Propensity for lung metastasis. Alexandria J Med. 2014; 50(3):203-9. doi: 10.1016/j.ajme.2014.01.003 
21. Bando H, Yoshino T, Yuki S, Shinozaki E, Nishina T, Kadowaki S, et al. Clinical outcome of Japanese metastatic colorectal cancer patients harbouring the KRAS p.G13D mutation treated with cetuximab + irinotecan. Jpn J Clin Oncol. 2012;42(12):1146-51. doi: 10.1093/jjco/hys160

22. Calistri D, Rengucci C, Seymour I, Lattuneddu A, Polifemo AM, Monti F, et al. Mutation analysis of p53, K-ras, and BRAF genes in colorectal cancer progression. J Cell Physiol. 2005;204(2):484-8.

23. Di Fiore F, Blanchard F, Charbonnier F, Le Pessot F, Lamy A, Galais MP, et al. Clinical relevance of KRAS mutation detection in metastatic colorectal cancer treated by Cetuximab plus chemotherapy. Br J Cancer. 2007;96(8):1166-9

24. Gajate P, Sastre J, Bando I, Alonso T, Cillero L, Sanz J, et al. Influence of KRAS p.G13D mutation in patients with metastatic colorectal cancer treated with cetuximab. Clin Colorectal Cancer. 2012;11(4):2916. doi: 10.1016/j.clcc.2012.02.003

25. Lièvre A, Bachet JB, Boige V, Cayre A, Le Corre $\mathrm{D}$, Buc E, et al. KRAS mutations as an independent prognostic factor in patients with advanced colorectal cancer treated with cetuximab. J J Clin Oncol. 2008;26(3):374-9. doi: 10.1200/ JCO.2007.12.5906

26. Mellbin LG, Malmberg K, Rydén L, Wedel H, Vestberg D, Lind M. The relationship between glycaemic variability and cardiovascular complications in patients with acute myocardial infarction and type 2 diabetes: a report from the DIGAMI 2 trial. Eur Heart J. 2013 Feb;34(5):374-9. doi: 10.1093/ eurheartj/ehs384

27. Pandey NR, Bian YY, Shou ST. Significance of blood pressure variability in patients with sepsis. World J Emerg Med. 2014;5(1):42-7. doi: 10.5847/ wjem.j.1920-8642.2014.01.007

28. Kilpatrick ES, Rigby AS, Goode K, Atkin SL. Relating mean blood glucose and glucose variability to the risk of multiple episodes of hypoglycaemia in type 1 diabetes. Diabetologia. 2007;50(12):2553-61

29. Dias de Carvalho T, Marcelo Pastre C, Claudino Rossi R, de Abreu LC, Valenti VE, Marques Vanderlei LC. Índices geométricos de variabilidade da frequência cardíaca na doença pulmonar obstrutiva crônica. Rev Port Pneumol. 2011;17(6):2605. doi: 10.1016/j.rppneu.2011.06.007 